\title{
A comparative study of sexual attitudes towards lesbianism and homosexuality with reference to age and gender
}

\author{
Simran $\operatorname{Sharma}^{1} *$
}

\section{ABSTRACT}

The aim of the present study was to find out whether age and gender have an influence on the sexual attitudes of people. The following components of sexual attitude were studied namely: Attitude towards lesbianism and homosexuality. The sample consisted of 100 subjects in which 50 were from the age group of $18-28$ years further divided equally with respect to gender (25-male, 25-female) and the other 50 in the age group of 50-60 years similarly divided into male and female. $2 \times 2$ Factorial design was used as the research design for the present study. The sample was first divided in two groups on the basis of age and then further on the basis of gender. Personal data sheet and a questionnaire titled 'Sexual Attitude Scale' developed by Amit Abraham was used for data collection. Gathered data was calculated and analysed by F-test (ANOVA). The results revealed that subjects in the age group of 18-28 years had a favourable sexual attitude and 50-60 years had an unfavourable sexual attitude. On the basis of gender, males showed a favourable sexual attitude over females. While studying the interaction of age and gender on sexual attitudes it was found that males in the age group of 18-28 years had the most favourable sexual attitude whereas the females in the age groups of 50-60 years had the least favourable sexual attitude.

Keywords: Sexual Attitudes; Homosexuality; Lesbianism

Homosexuality was never accepted happily in the society specially in the Indian context. People still hold an orthodox approach towards different sexual orientations. For a good amount of time homosexuality was considered a mental illness. But in the recent times the social picture is starting to change. Youngsters are more open to embrace their homosexual friends, family, and colleagues, and adults care enough to make an effort to understand that their world is not wrong but a little different from us.

(Almeida, Johnson, Corliss, Molnar, \& Azrael, 2009) talk about how the homosexual individuals face emotional distress more than the heterosexual individuals. This is alarming because young people facing severe emotional distress due to their sexual orientation is not favourable for their growth or their emotional and social development. (Meuher, 1995) has talked about the influence of one's sexual orientation on their suicidal tendencies. The rates have been higher in the bisexual and homosexual individuals which also directs us to know

${ }^{1}$ Research Scholar, St. Xavier's College, Ahmedabad, India

*Responding Author

Received: October 22, 2019; Revision Received: December 14, 2019; Accepted: December 25, 2019

(C) 2019, S Sharma; licensee IJIP. This is an Open Access Research distributed under the terms of the Creative Commons Attribution License (www.creativecommons.org/licenses/by/2.0), which permits unrestricted use, distribution, and reproduction in any Medium, provided the original work is properly cited. 


\section{A Comparative Study Of Sexual Attitudes Towards Lesbianism and Homosexuality With Reference to Age and Gender}

that homosexuals are more prone to several mental illnesses. The cause of this has deep roots in the social treatment given to them at their home, in schools, in workplaces, and more. It is important for people to stop treating them differently just because of their sexual orientation. (Saewyc, 2011) has talked about the several health disparities homosexuals go through. He has also focussed on the development of them. The studies found that homosexuals develop similar to the heterosexuals individuals. Their cognitive, motor, or sensory development is not influenced by their sexual orientation.

With the amendments in section 377 last year, the government has taken a step forward in accepting the queer community. (Narrain, 2019) has talked about the various perspectives about the recent section 377 . The articles focusses on the practical implications of the section 377 amendment. One of the perspectives say that this verdict has broken the queer movement because the more privileged in the queer community do not want to be involved in more fights now. Others have pointed out that the amendment was legal but the society is yet to go a long way in accepting them and their sexual orientation. Some have also told that the verdict has made people more receptive of their sexuality and many people have come out to their friends and family about their sexual orientation. Coming out at their workplace has also been easier for them.

There are several problems faced by the homosexuals. This research paper is focussed on the sexual attitude of people towards lesbianism and homosexuality.

\section{LITERATURE REVIEW}

(Herek, 2004) has talked about the homophobia that prevails in the society. $\mathrm{He}$ has also focussed on the sexual stigma that has been haunting the members of the society since the last $19^{\text {th }}$ century. This paper focuses on the stigma and the discrimination of the homosexuals in the $21^{\text {st }}$ century. This paper gives the base to studies considering the in-depth work done on the people's sexual attitude towards homosexuality and how homophobia is a result of the same. It also talks about constructs like sexual stigma, heterosexism, and sexual prejudice. Internalized homophobia is also a concept in focus in the paper by the author.

In their paper (Day \& Schoenrade, 2000) talk about sexual orientation and the antidiscriminatory policies in the work places. The paper had three major variables, namely, sexual orientation, anti-discrimination policies, and top management support for equal rights with relevant work attitudes. All the variables were related to the affective organization commitment and an individual's conflict between work and home. However the antidiscrimination policies and the top management support are more related to the job satisfaction experienced by an individual. It was found that 'closeted' homosexuals did not face much issue at the workplace. However, it was seen that human resource professionals try to bring in a safer work attitude for homosexuals by educating the top managers first. This is important since they influence a larger workforce that works under them.

In a research study (Jorm, Korten, Rodgers, Jacomb, \& Christensen, 2018) have talked about the influence of an individual's sexual orientation on their mental health. One group consists of the homosexuals and the bisexuals, whereas the other group consists of the heterosexuals. The community survey was conducted on 4825 adults in Australia. The survey focussed on topics such as anxiety, depression, suicidality, alcohol misuse, positive and negative affects and many other factors of poorer mental health. The results of the research indicated that the 


\section{A Comparative Study Of Sexual Attitudes Towards Lesbianism and Homosexuality With Reference to Age and Gender}

bisexuals scored highest on anxiety, depression and the negative affect. Homosexuals scored higher than heterosexuals but lower than bisexuals putting them between the two groups.

(Marshal, et al., 2008) have talked about the influence of sexual orientation on the adolescent substance use through a meta-analysis and a methodological review. The aim of the paper was to clearly define the substance abuse ratios and the substance use disorders rates among the youth based on their sexual orientation. The results of the research studies showed that the LGB (Lesbian, Gay, Bisexual) adolescents showed higher substance use in their daily life than the heterosexual teenagers. The results were even more staggering when the subpopulations were considered. The substance use rates were higher in women by $400 \%$ and the bisexuals reported a $340 \%$ higher substance use than the homosexuals. The aggregated LGB group showed a $190 \%$ higher consumption of various substances than the heterosexuals.

\section{METHODOLOGY}

\section{Sample}

A sample of 100 subjects was selected for the research. They are first divided on the basis of Age; that is, 50 subjects under the age group of 18 to 28 years and 50 subjects under the age group of 50-60 years. They are further divided on the second level on the basis of gender. In the age group of 18 to 28 years the subjects are divided further on the basis of gender; that is 25 males and 25 females. Similarly, in the age group of 50 to 60 years the subjects are divided further on the basis of gender; that is 25 males and 25 females. The sexual attitude scale by Amit Abraham was administered to them.

\section{Instruments}

Two measures were used in this study,

\section{Personal Information}

Personal information was gathered from all the subjects like their name, age, gender, education qualification, profession and religion.

\section{Sexual Attitude Scale (S.A.S.)}

Sexual Attitude Scale developed by Amit Abraham, was a lecturer at the Department of Psychology in St John's College, Agra. The Sexual Attitude Scale measures an individual's attitude towards five aspects separately, namely premarital sex, monogamy, pornography, lesbianism and homosexuality. Each of these are considered as individual scales. Lesbianism and Homosexuality sexual attitude scales were used for this research study.

\section{Procedure}

The purpose of the present investigation was to study the sexual attitudes of people in two different age groups. For this study it was decided to select 100 subjects $(50-18-28$ years of age; 50 - 50-60 years of age). Initially a list for all the categories of subjects was prepared. To prepare the list of subjects randomization technique was used.

In this way two groups were prepared. In the beginning 100 subjects in each group were randomly selected on the basis of their response on our online google forms which were distributed to 215 samples randomly. Out of these, 100 forms with complete responses were selected as the research sample. Among these were 50 from the 18-28 years of age (25-male; 25- females) and same for the other age group. Sexual attitude scale was administered, and the information was collected. The investigator obtained helping getting necessary cooperation from the subjects and assured them that responses would be kept strictly 
confidential and would be utilized for research purposes only. After that the data were collected according to their convenience.

\section{RESULTS}

Attitude towards Lesbianism

Table 1 Shows Anova Results on LS

\begin{tabular}{|c|c|c|c|c|c|}
\hline SOV & Df & $\begin{array}{c}\text { Sum of } \\
\text { Squares }\end{array}$ & Mean Square & F & Significance \\
\hline SSA & 1 & 1089 & 1089 & 9.93 & $* *$ \\
\hline SSB & 1 & 817.96 & 817.96 & 7.46 & $* *$ \\
\hline SSAB & 1 & 2435.96 & 2435.96 & 22.21 & $* *$ \\
\hline SSE & 96 & 10521.84 & 109.64 & & \\
\hline SST & 99 & 14864.76 & 150.14 & & \\
\hline
\end{tabular}

Table 2 Shows Mean Scores And Mean Differences Between Age And Gender On LS

\begin{tabular}{|c|c|c|c|}
\hline Independent Variable & $\mathbf{N}$ & Mean & Mean Difference \\
\hline Age group (18-28) & 50 & 37.48 & 6.6 \\
\hline Age group (50-60) & 50 & 30.88 & 5.72 \\
\hline Male & 50 & 37.04 & \\
\hline Female & 50 & 31.32 & \\
\hline
\end{tabular}

Table 3 Shows Mean Scores of Interactions Between Age And Gender On LS

\begin{tabular}{|c|c|c|}
\hline LS & $\begin{array}{c}\text { Age 18-28 years } \\
\text { (A1) }\end{array}$ & $\begin{array}{c}\text { Age 50-60 years } \\
\text { (A2) }\end{array}$ \\
\hline Male (B1) & 38.04 & 36.04 \\
\hline Female (B2) & 36.92 & 25.72 \\
\hline
\end{tabular}

\section{LS with reference to age (18-28 \& 50-60 Years)}

The results of ANOVA on sexual attitude score Table 1 is consulted and it is found that Fratio for age groups is 9.93 , which is significant at 0.01 levels. This means sexual attitude in people from 18-28 years of age differs significantly from sexual attitude in people from 50-60 years of age. Table 2 shows the mean scores of the age group 18-28 years as 37.48 and of the age group 50-60 years as 30.88. The difference between the mean scores is 6.6. It is clearly said that significant difference existed between the age groups of 18-28 years and 50-60 years on their sexual attitudes. Thus, the null-hypothesis is rejected.

\section{$L S$ with reference to gender (Male \& Female)}

The results of ANOVA on sexual attitude score Table 1 is consulted and it is found that Fratio for gender is 7.46 , which is significant at 0.01 levels. This means sexual attitude in males differs significantly from sexual attitude in females. Table 2 shows the mean scores of males as 37.04 and of females as 31.32. The difference between the mean scores is 5.72. It is clearly said that significant difference existed between males and females on their sexual attitudes. Thus, the null-hypothesis is rejected.

\section{$L S$ with reference to interaction of age and gender}

So the present research decided to go for identifying such interactive effect between the age and gender on the total score of sexual attitude in the subjects. 
There are four interaction effect were found, these are A1B1, A1B2, A2B1 and A2B2. The result of ANOVA on sexual attitude is consulted and it is found that F-ratio for sexual attitude towards lesbianism with reference to interaction of age and gender is 22.21 which is significant on 0.01 levels. According to Table 2, there are significant mean differences in all the four interactions given above.

In the first interaction A1B1 and A1B2, it consists of males and females in the age groups of 18-28 years of age. Table 3 shows that the mean score of males in the age group of 18-28 years of age group is 38.04 and the mean score of females in the age group of 18-28 years of age group is 39.62 . The mean difference here is 1.12 which is not significant. This shows that in the age group of 18-28 years there is no significant difference in the sexual attitude towards lesbianism with reference to gender.

In the second interaction $\mathrm{A} 2 \mathrm{~B} 1$ and $\mathrm{A} 2 \mathrm{~B} 2$, it consists of males and females in the age groups of 50-60 years of age. Table 3 shows that the mean score of males in the age group of 50-60 years of age group is 36.04 and the mean score of females in the age group of 50-60 years of age group is 25.72 . The mean difference here is 10.32 which is clearly significant. This shows that in the age group of 50-60 years of age there is significant difference in the sexual attitude towards lesbianism with reference to gender. This means age and gender interacts with each other on sexual attitude towards lesbianism.

In the third interaction $\mathrm{A} 1 \mathrm{~B} 1$ and $\mathrm{A} 2 \mathrm{~B} 1$, it consists of males in the age groups of 18-28 years of age and 50-60 years of age. Table 3 shows that the mean score of males in the age group of 18-28 years of age is 38.04 and the mean score of males in the age group of 50-60 years of age group is 36.04. The mean difference here is 2 which is not significant. This shows that males in the age group of 18-28 years of age and 50-60 years of age have no significant difference in the sexual attitude towards lesbianism with reference to age. This means that males in both the age groups interact with each other on sexual attitude towards lesbianism.

In the fourth interaction A1B2 and A2B2, it consists of females in the age groups of 18-28 years of age and 50-60 years of age. Table 3 shows that the mean score of females in the age group of 18-28 years of age is 39.62 and the mean score of females in the age group of 50-60 years of age group is 25.72 . The mean difference here is 13.9 which is clearly significant. This shows that females in the age group of 18-28 years of age and 50-60 years of age have significant difference in the sexual attitude towards lesbianism with reference to age. This means that males in both the age groups interact with each other on sexual attitude towards lesbianism.

Attitude Towards Homosexuality

Table 4 Shows Anova Results on HS

\begin{tabular}{|c|c|c|c|c|c|}
\hline SOV & Df & $\begin{array}{c}\text { Sum of } \\
\text { Squares }\end{array}$ & $\begin{array}{c}\text { Mean } \\
\text { Square }\end{array}$ & F & Significance \\
\hline SSA & 1 & 767.29 & 767.29 & 8.58 & $* *$ \\
\hline SSB & 1 & 193.21 & 193.21 & 2.16 & NS \\
\hline SSAB & 1 & 1915.31 & 1915.31 & 21.43 & $* *$ \\
\hline SSE & 96 & 8576.7 & 89.34 & & \\
\hline SST & 99 & 11452.51 & 115.68 & & \\
\hline
\end{tabular}


Table 5 Shows Mean Scores and Mean Differences between Age and Gender on HS

\begin{tabular}{|c|c|c|c|}
\hline $\begin{array}{c}\text { Independent } \\
\text { Variable }\end{array}$ & $\mathbf{N}$ & Mean & Mean Difference \\
\hline Age group (18-28) & 50 & 31.7 & 5.54 \\
\hline Age group (50-60) & 50 & 26.16 & \\
\hline Male & 50 & 30.32 & 2.78 \\
\hline Female & 50 & 27.54 & \\
\hline
\end{tabular}

Table 6 Shows Mean Scores of Interactions between Age and Gender On HS

\begin{tabular}{|c|c|c|}
\hline LS & $\begin{array}{c}\text { Age 18-28 years } \\
(\mathbf{A 1})\end{array}$ & $\begin{array}{c}\text { Age 50-60 years } \\
(\mathbf{A 2})\end{array}$ \\
\hline Male (B1) & 30 & 30.64 \\
\hline Female (B2) & 33.4 & 21.68 \\
\hline
\end{tabular}

\section{HS with Reference to Age (18-28 \& 50-60 Years)}

The results of ANOVA on sexual attitude score Table 1 is consulted and it is found that Fratio for age groups is 8.58 , which is significant at 0.01 levels. This means sexual attitude in people from 18-28 years of age differs significantly from sexual attitude in people from 50-60 years of age. Table 2 shows the mean scores of the age group 18-28 years as 31.7 and of the age group 50-60 years as 26.16. The difference between the mean scores is 5.54. It is clearly said that significant difference existed between the age groups of 18-28 years and 50-60 years on their sexual attitudes. Thus, the null-hypothesis is rejected.

\section{HS with Reference to Gender (Male \& Female)}

The results of ANOVA on sexual attitude score Table 1 is consulted and it is found that Fratio for gender is 2.16, which is not significant. This means sexual attitude in males differs significantly from sexual attitude in females. Table 2 shows the mean scores of males as 30.32 and of females as 27.54 . The difference between the mean scores is 2.78 . It is clearly said that significant difference existed between males and females on their sexual attitudes. Thus, the null-hypothesis is accepted.

\section{HS with Reference to Interaction of Age and Gender}

The present research decided to go for identifying such interactive effect between the age and gender on the total score of sexual attitude in the subjects. There are four interaction effect were found, these are $\mathrm{A} 1 \mathrm{~B} 1, \mathrm{~A} 1 \mathrm{~B} 2, \mathrm{~A} 2 \mathrm{~B} 1$ and $\mathrm{A} 2 \mathrm{~B} 2$. The result of ANOVA on sexual attitude is consulted and it is found that F-ratio for sexual attitude towards lesbianism with reference to interaction of age and gender is 89.34 which is significant on 0.01 levels. According to Table 2, there are significant mean differences in all the four interactions given above.

In the first interaction A1B1 and A1B2, it consists of males and females in the age groups of 18-28 years of age. Table 3 shows that the mean score of males in the age group of 18-28 years of age group is 30.64 and the mean score of females in the age group of 50-60 years of age group is 30.64. The mean difference here is 0.64 which is not significant. This shows that in the age group of 18-28 years there is no significant difference in the sexual attitude towards homosexuality with reference to gender. 


\section{A Comparative Study Of Sexual Attitudes Towards Lesbianism and Homosexuality With Reference to Age and Gender}

In the second interaction $\mathrm{A} 2 \mathrm{~B} 1$ and $\mathrm{A} 2 \mathrm{~B} 2$, it consists of males and females in the age groups of 50-60 years of age. Table 3 shows that the mean score of males in the age group of 50-60 years of age group is 30.64 and the mean score of females in the age group of 50-60 years of age group is 21.68 . The mean difference here is 8.96 which is clearly significant. This shows that in the age group of 50-60 years of age there is significant difference in the sexual attitude towards homosexuality with reference to gender. This means age and gender interacts with each other on sexual attitude towards homosexuality.

In the third interaction A1B1 and A2B1, it consists of males in the age groups of 18-28 years of age and 50-60 years of age. Table 3 shows that the mean score of males in the age group of 18-28 years of age is 30 and the mean score of males in the age group of 50-60 years of age group is 30.64 . The mean difference here is 0.64 which is not significant. This shows that males in the age group of 18-28 years of age and 50-60 years of age have no significant difference in the sexual attitude towards lesbianism with reference to age. This means that males in both the age groups interact with each other on sexual attitude towards homosexuality.

In the fourth interaction $\mathrm{A} 1 \mathrm{~B} 2$ and $\mathrm{A} 2 \mathrm{~B} 2$, it consists of females in the age groups of 18-28 years of age and 50-60 years of age. Table 3 shows that the mean score of females in the age group of 18-28 years of age is 33.4 and the mean score of females in the age group of 50-60 years of age group is 21.68 . The mean difference here is 11.72 which is clearly significant. This shows that females in the age group of 18-28 years of age and 50-60 years of age have significant difference in the sexual attitude towards homosexuality with reference to age. This means that males in both the age groups interact with each other on sexual attitude towards homosexuality.

\section{DISCUSSION}

\section{Attitude Towards Lesbianism}

\section{$L S$ with reference to age (18-28\& 50-60 Years)}

In the present study results revealed that people from 18-28 years of age had a liberal and favourable sexual attitude towards lesbianism and people from 50-60 years of age had a rigid and unfavourable sexual attitude towards lesbianism. There were several causes which had an impact on these results. Let's see some of the causes as follows:

1. Homophobia has been very prevalent in the Indian society for a very long time now. People and the society has had a big problem accepting people with a different sexual orientation other than heterosexuality. They have believed that true love can exist only between a man and a woman. An acceptable sexual relationship can exist only between a man and a woman. This homophobia is much more prevalent in the elder generation i.e. for people in the age group of 50-60 years of age as homosexuality was never discussed openly in almost their entire lifetime which results in the unfavourable sexual attitude they have for lesbians.

2. Youngster i.e. people in the age group of 18-28 years of age have a favourable sexual attitude towards lesbianism is because they have seen discussions and debates talking openly about homosexuality. They have seen people come out openly about their sexual orientation and have sensitized to the same, resulting in the favourable sexual attitude towards lesbianism. 


\section{LS with reference to gender (Male \& Female)}

In the present study results revealed that males had a liberal and favourable sexual attitude towards lesbianism and females had a rigid and unfavourable sexual attitude towards lesbianism.

There were several causes which had an impact on these results.

1. Females have an unfavourable attitude towards lesbianism because of the deeper inhibition exhibited by the society. Since the olden times, female sexuality has not been given as much importance. Females never had the right to enjoy their sexuality and did not have a say in the same. Even in heterosexual relationships females were always seen as to satisfy the sexual needs of her male partner and not to satisfy her own. Female sexuality was never as much acknowledged in a heterosexual relationship. Henceforth, a lesbian relationship is far away from the questions of the society. It could never be accepted by the society that two females are together in a sexual relationship to consider and satisfy their sexual needs. Lesbianism has always had more criticism than homosexuality because of this factor.

2. Gender bias also came into the picture as males felt of no use when they heard of lesbian relationships. It is always the male partner who is the head of the relationship and the family in the Indian society. This image and norm is distorted is a lesbian relationship which is not acceptable by the society as a whole.

3. Females also have an unfavourable attitude towards lesbianism because of the mindset created by the society that it was bad for a girl to enjoy sex. Sex was seen as something dirty or a sin. Males were exempted from this mindset. Females were taught that they were being married to a man and it is her duty to satisfy his sexual needs. This norm was internalized by the women of the society centuries ago. Now this shows up in their sexual attitude towards lesbianism.

\section{Attitude Towards Homosexuality}

\section{HS with Reference to Age (18-28 \& 50-60 Years)}

In the present study results revealed that people from 18-28 years of age had a liberal and favourable sexual attitude towards lesbianism and people from 50-60 years of age had a rigid and unfavourable sexual attitude towards homosexuality. There were several causes which had an impact on these results. Let's see some of the causes as follows:

1. Homophobia has been very prevalent in the Indian society for a very long time now. People and the society has had a big problem accepting people with a different sexual orientation other than heterosexuality. They have believed that true love can exist only between a man and a woman. An acceptable sexual relationship can exist only between a man and a woman. This homophobia is much more prevalent in the elder generation i.e. for people in the age group of 50-60 years of age as homosexuality was never discussed openly in almost their entire lifetime which results in the unfavourable sexual attitude they have for lesbians.

2. Youngster i.e. people in the age group of 18-28 years of age have a favourable sexual attitude towards lesbianism is because they have seen discussions and debates talking openly about homosexuality. They have seen people come out openly about their sexual orientation and have sensitized to the same, resulting in the favourable sexual attitude towards lesbianism. 


\section{HS with Reference to Gender (Male \& Female)}

It was observed that gender did not have a significant influence on the sexual attitude towards homosexuality in all age groups considered. This can be due to the societal influence and the stereotypical gender roles that have been imposed on individuals.

\section{REFERENCES}

Almeida, J., Johnson, R., Corliss, H., Molnar, B., \& Azrael, D. (2009). Emotional Distress Among LGBT Youth: The Influence of Perceived Discrimination Based on Sexual Orientation. Journal of Youth and Adolescence, 1001-1014.

Day, N., \& Schoenrade, P. (2000). The relationship among reported disclosure of sexual orientation, anti-discrimination policies, top management support and work attitudes of gay and lesbian employees. Personnel Review, 346-363.

Herek, G. (2004). Beyond "Homophobia": Thinking About Sexual Prejudice and Stigma in the Twenty-First Century . Sexuality Research \& Social Policy , 6-24.

Jorm, A., Korten, A., Rodgers, B., Jacomb, P., \& Christensen, H. (2018). Sexual orientation and mental health: results from a community survey of young and middle - aged adults. Cambridge University Press, 423-427.

Marshal, M., Friedman, M., Stall, R., Miles, J., King, K., Gold, M., . . Morse, J. (2008). Sexual orientation and adolescent substance use: a meta-analysis and methodological review*. Addiction, 446-456.

Meuher, P. (1995). Suicide and Sexual Orientation: A Critical Summary of Recent Research and Directions for Future Research. Suicide \& Life-Threatning Behavior, 72-81.

Narrain, A. (2019, September 6). Section 377 judgment on same sex relations: One year later, has anything changed? Retrieved from www.thehindu.com: https://www.thehindu.com/society/section-377-judgement-one-year-later/article29342570.ece

Saewyc, E. (2011). Research on Adolescent Sexual Orientation: Development, Health Disparities, Stigma, and Resilience. Journal of Research on Adolescence, 256-272.

\section{Acknowledgements}

I owe my gratitude to the Principal of St. Xavier's College Rev. Fr. (Dr.) Robert Arockiasamy, who has provided us with this astounding opportunity. I would also like to thank Dr. Sebastian Vadakan, Vice Principal (Research and Quality Assurance) who invoked the idea of scientific study in me and gave me an opportunity to learn about my subject outside the classroom. I am greatly indebted to my Head of the Department (Psychology) Dr. Khushnuma P. Banaji who has always been motivating throughout. Thank you for extending your valuable support at every stage of the research. I am very grateful to my guide professor Dr. Profaina Christian who has constantly been there to guide me at every stage of the research. Her optimism has always inspired me and has driven me to explore more on my topic. I truly value the constant support of my friends throughout this journey. Last but not the least I am deeply grateful for all the support and encouragement extended by my family that kept me motivated. I dedicate my research to all.

\section{Conflict of Interest}

The author declared no conflict of interests. 
How to cite this article: S Sharma (2019). A comparative study of sexual attitudes towards lesbianism and homosexuality with reference to age and gender. International Journal of Indian Psychology, 7(4), 413-422. DIP:18.01.049/20190704, DOI:10.25215/0704.049 